\title{
The role for osmotic agents in children with acute encephalopathies: a systematic review
}

\author{
Samson Gwer ${ }^{1,2^{*}}$, Hellen Gatakaa ${ }^{2,3}$, Leah Mwai ${ }^{1,2}$, Richard Idro ${ }^{1,4}$, Charles R Newton ${ }^{1,5,6}$
}

\begin{abstract}
Background: Raised intracranial pressure (ICP) is known to complicate both traumatic and non-traumatic encephalopathies. It impairs cerebral perfusion and may cause death due to global ischaemia and intracranial herniation. Osmotic agents are widely used to control ICP. In children, guidelines for their use are mainly guided by adult studies. We conducted this review to determine the current evidence of the effectiveness of osmotic agents and their effect on resolution of coma and outcome in children with acute encephalopathy.

Methods: We searched several databases for published and unpublished studies in English and French languages, between January 1966 and March 2009. We considered studies on the use of osmotic agents in children aged between 0 and 16 years with acute encephalopathies. We examined reduction in intracranial pressure, time to resolution of coma, and occurrence of neurological sequelae and death.

Results: We identified four randomized controlled trials, three prospective studies, two retrospective studies and one case report. Hypertonic saline (HS) achieved greater reduction in intracranial pressure (ICP) compared to mannitol and other fluids; normal saline or ringer's lactate. This effect was sustained for longer when it was given as continuous infusion. Boluses of glycerol and mannitol achieved transient reduction in ICP. Oral glycerol was associated with lower mortality and neurological sequelae when compared to placebo in children with acute bacterial meningitis. HS was associated with lower mortality when compared to mannitol in children with nontraumatic encephalopathies.
\end{abstract}

Conclusion: HS appears to achieve a greater reduction in ICP than other osmotic agents. Oral glycerol seems to improve outcome among children with acute bacterial meningitis. A sustained reduction in ICP is desirable and could be achieved by modifying the modes and rates of administration of these osmotic agents, but these factors need further investigation.

\section{Background}

Raised intracranial pressure (ICP) is a recognized feature of both traumatic and non-traumatic encephalopathies [1-4]. It impairs cerebral perfusion pressure (CPP), leading to ischaemia, and may cause death by compressing the brainstem during intracranial herniation. Raised ICP has consistently been shown to be an important determinant of outcome in children with central nervous system (CNS) infections and traumatic brain injuries (TBI) $[1,4,5]$. Management of raised ICP is aimed at optimizing CPP and oxygen supply to the brain in addition to reducing ICP. Methods to reduce ICP include postural changes, temperature regulation, hyperventilation,

\footnotetext{
* Correspondence: sgwer@kilifi.kemri-wellcome.org

${ }^{1}$ Centre for Geographic Medicine Research (Coast), KEMRI-Wellcome Trust Collaborative Research Programme, Kilifi, Kenya
}

sedation, drainage of cerebro-spinal fluid, operative decompression, and the most widely used, osmotherapy [6-8].

Osmotherapy entails the use of pharmacologically inert substances that increase the osmotic pressure of plasma, promoting movement of water from interstitial space to vascular space [9]. Osmotic agents include mannitol, urea, sorbitol, glycerol and hypertonic saline (HS). Although these agents act mainly by reducing ICP via an osmotic gradient, they may have other beneficial effects. Thus, mannitol has been shown to scavenge reactive oxygen species [10], reduce the viscosity of blood, improving its flow through the circulation [11], and cause vasoconstriction, reducing cerebral blood volume [12]. Hypertonic saline is an effective volume expander which improves systemic haemodynamics and
C Biomed Central

(c) 2010 Gwer et al; licensee BioMed Central Ltd. This is an Open Access article distributed under the terms of the Creative Commons Attribution License (http://creativecommons.org/licenses/by/2.0), which permits unrestricted use, distribution, and reproduction in any medium, provided the original work is properly cited. 
increases CPP [13]. In animal models, it has also been shown to enhance cerebral microcirculation by reducing adhesions of polymorphonuclear cells and by stimulating local release of nitric oxide [14].

Guidelines for use of osmotic agents have been developed from adult TBI studies. However, these have been adapted for children with minimal evidence obtained directly from children with TBI. Among children with non-traumatic encephalopathies, guidelines are virtually non-existent. In a postal survey of raised ICP management protocols in UK hospitals, practices varied greatly between hospitals [15]. Monitoring for patients with non-traumatic encephalopathy was seldom considered and thus, little consideration was given for use of osmotic agents in this group.

We performed this review to determine the best available evidence on the effectiveness of various osmotic agents and their effect on resolution of coma and outcome (neurological sequelae and mortality) in children with acute encephalopathies.

\section{Method}

This review examines the effectiveness of osmotic agents in reducing ICP in children with acute encephalopathies and, the effect of osmotic agents on resolution of coma and clinical outcome (neurological sequelae and mortality) in children with acute encephalopathies.

\section{Inclusion criteria}

We searched published and unpublished studies in the English and French languages between January 1966 and March 2009. We reviewed randomized controlled trials with the aim of performing a meta-analysis. In addition, we examined quasi- and non-randomized clinical trials, case control, cohort, and before and after studies, case series, and case reports, for consideration in a narrative summary.

We evaluated studies that included children aged between 0 and 16 years with acute traumatic and nontraumatic encephalopathies, characterized by altered consciousness. Agents included in our search were mannitol, hypertonic saline, urea, sorbitol and glycerol. The primary outcome measure was reduction in ICP. Secondary outcome measures were resolution of coma and clinical outcome (neurological sequelae and death).

\section{Search Strategy}

We searched Pubmed, Cochrane library, EMBASE and cumulative index to nursing and allied health literature (CINAHL). Other databases included were current controlled trials, the trials register for promoting health interventions (TRoPHI), Australian clinical trials registry (ACTR), clinical medicine net prints collection, Bandolier evidence based health care, and the center for clinical trials and evidence-based healthcare at Brown medical school. The search databases for unpublished studies and grey literature were dissertation abstracts international, the World Health Organization library, Agency for Healthcare Research and Quality, Grey literature report, National Library of Medicine, theses Canada portal, Proquest digital theses, Australasian digital theses program and the British library. The initial search analyzed the text words contained in the title and abstract, and the index terms used to describe the articles. A second search that used all identified keywords and index terms, individually and in combinations, was applied. The reference list of all identified reports and articles were then searched for additional studies. In our search in Pubmed, we applied the search phrase "(mannitol [MeSH] OR hypertonic saline $[\mathrm{MeSH}]$ OR urea $[\mathrm{MeSH}]$ OR sorbitol $[\mathrm{MeSH}]$ OR glycerol $[\mathrm{MeSH}])$ AND (hepatic encephalopathy [MeSH] OR malaria, cerebral [MeSH] OR meningitis [MeSH] OR encephalitis $[\mathrm{MeSH}]$ OR brain injuries [MeSH] OR head injuries $[\mathrm{MeSH}]$ OR coma $[\mathrm{MeSH}] \mathrm{OR}$ intracranial hypertension $[\mathrm{MeSH}])$ )" and limited it to children, the English and French languages, and the duration between $1^{\text {st }}$ of January 1966 and $31^{\text {st }}$ March 2009, and children."

\section{Assessment of studies}

The papers selected for retrieval were assessed by two independent reviewers for methodological validity prior to inclusion in the review. We used the standardized critical appraisal instruments from the Joanna Briggs Institute Meta-Analysis of Statistics Assessment and Review Instrument (JBI-MAStARI) Critical Appraisal tool [16]. Any disagreements between the reviewers were resolved through discussion, or with a third reviewer. We extracted data using the standardized JBI data extraction tool [16]. All data were entered twice and discrepancies resolved. We considered quantitative studies for pooling for statistical meta-analysis. Relative risk and their $95 \%$ confidence intervals $(95 \% \mathrm{CI})$ were calculated for analysis. Other findings were presented in a narrative form.

The protocol that guided this review is available, on request, from the review protocols section of the Joanna Briggs institute website; http://www.joannabriggs.edu.au/ pubs/systematic_reviews_prot.php

\section{Results}

Our search of the databases revealed 291 records. We identified 20 studies that met our review criteria. We critically appraised them using the JBI-MASTARI assessment tool and excluded 10 studies. The different phases of the review are summarized in figure 1. Four of the studies excluded did not provide any data or information on the relationship between the interventions 


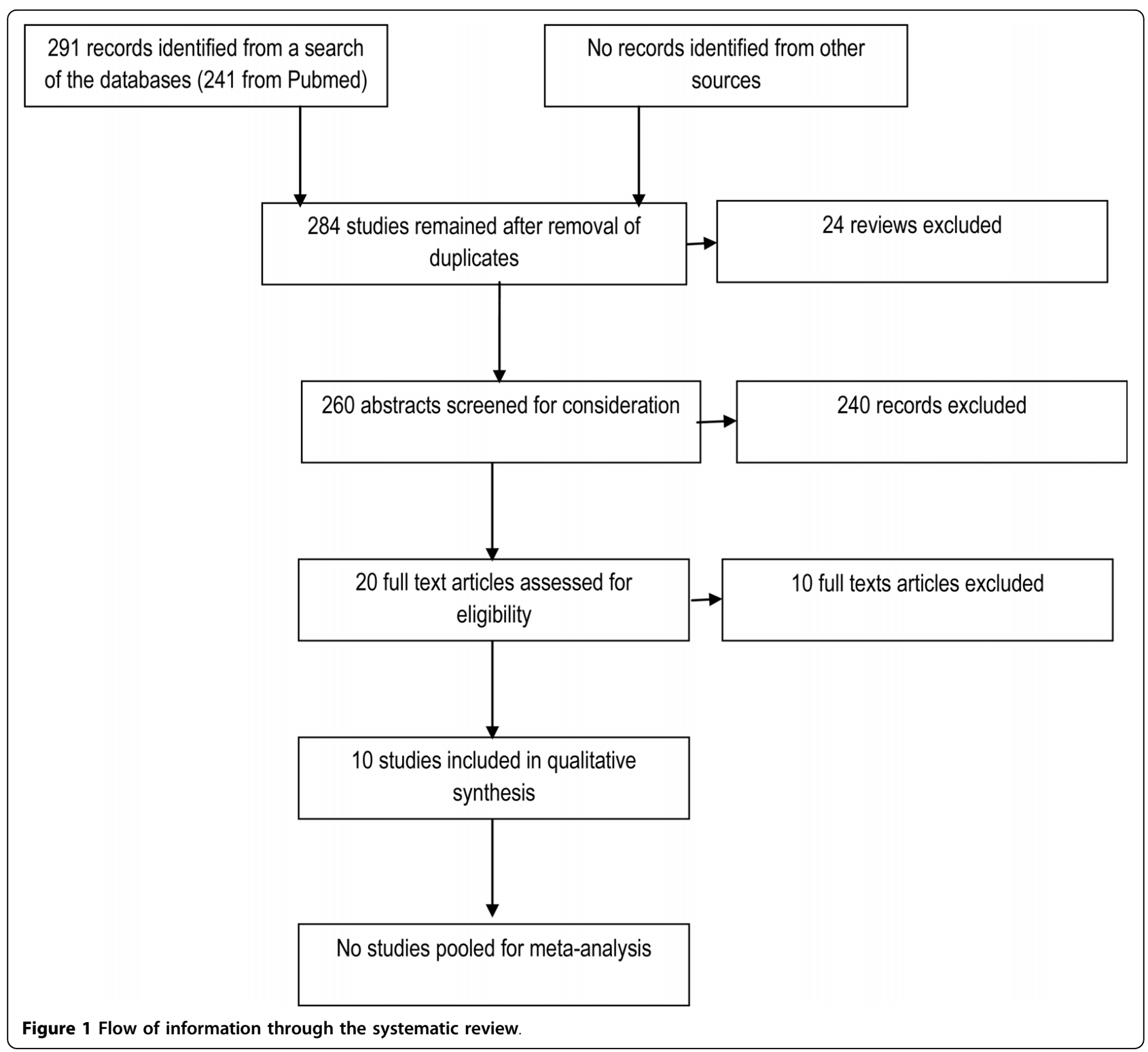

and the outcomes of interest [17-20]. Three studies included children and adults but data on children were not provided separately nor could we obtain this information from the authors [21-23]. Two other studies were excluded for other reasons [24,25] (Table 1).

We included four randomized controlled trials (RCTs) [26-29], one of which was a cross-over trial [26], three prospective observational studies $[1,30,31]$, two retrospective studies [32,33], and one case report [34]. Out of these, four studies involved patients with non-traumatic encephalopathies $[1,27,28,32]$. The characteristics of these studies (participants, interventions, comparisons, outcomes, and study design) are summarized in additional file 1. Among the clinical trials, assignment of treatment was random in all the studies, but in two studies, the allocation to treatment groups was not concealed from the investigators [26,29]. We assessed each study according to its study design as shown in tables 2 , 3 and 4.

\section{Intracranial Pressure}

ICP was monitored in 7 studies; 2 RCTs [26,29], 4 observational studies $[1,30,31,33]$ and one case report [34]. In one RCT, ringer's lactate was compared to HS for resuscitation of 32 children with traumatic brain injuries [29]. More interventions for raised ICP were used in the Ringer's lactate group compared to the HS group $(P<0.01)$ [29]. However, there was no significant difference in the mean ICPs between the two groups after the interventions. In a crossover trial that included 
Table 1 Reason for exclusion of studies

\begin{tabular}{|c|c|}
\hline Study & Reason for exclusion \\
\hline $\begin{array}{l}\text { Prabhakaran } \\
2004 \text { [19] }\end{array}$ & $\begin{array}{l}\text { The paper did not report on effect of the } \\
\text { intervention, mannitol, on ICP or outcome }\end{array}$ \\
\hline Vialet 2003 [23] & $\begin{array}{l}\text { The study provides combined results for adults and } \\
\text { children, and the data for children could not be } \\
\text { extracted }\end{array}$ \\
\hline $\begin{array}{l}\text { Kingston } 1971 \\
{[18]}\end{array}$ & $\begin{array}{l}\text { There is little information on the characteristics of the } \\
\text { participants. There is no data provided on the effect } \\
\text { of the intervention, urea, on ICP or outcome }\end{array}$ \\
\hline Cruz 2002 [17] & $\begin{array}{l}\text { The use of the intervention, mannitol, was not clearly } \\
\text { evaluated and the study does not demonstrate the } \\
\text { relationship between mannitol use and outcome }\end{array}$ \\
\hline James 1977 [22] & $\begin{array}{l}\text { The study provides combined the results for adults } \\
\text { and children, and the data on children could not be } \\
\text { extracted. }\end{array}$ \\
\hline James 1980 [21] & $\begin{array}{l}\text { The study provides combined the results for adults } \\
\text { and children, and the data on children could not be } \\
\text { extracted. }\end{array}$ \\
\hline $\begin{array}{l}\text { MacDonald } \\
1982[25]\end{array}$ & $\begin{array}{l}\text { Reason for selective data presentation not given and } \\
\text { administration of both treatments not clearly } \\
\text { described }\end{array}$ \\
\hline $\begin{array}{l}\text { Marshall } 1978 \\
{[24]}\end{array}$ & $\begin{array}{l}\text { Age of subjects is not given and unclear statistical } \\
\text { methods have been used }\end{array}$ \\
\hline $\begin{array}{l}\text { Mickell } 1977 \\
{[20]}\end{array}$ & $\begin{array}{l}\text { The relationship between the intervention and ICP or } \\
\text { outcome is not described }\end{array}$ \\
\hline $\begin{array}{l}\text { Procaccio } 1991 \\
\text { [36] }\end{array}$ & $\begin{array}{l}\text { The study included a heterogeneous age group of } \\
\text { patients that is not comparable and in whom } \\
\text { standard treatment was not provided to all }\end{array}$ \\
\hline
\end{tabular}

18 children with TBI, there was a significant drop from the initial ICP with use of $\mathrm{HS}(\mathrm{P}=0.003)$ compared to normal saline $(\mathrm{P}=0.32)$ [26].

Hypertonic saline given as a continuous infusion in a study of 10 children with TBI achieved a significant and sustained reduction of ICP that was maintained over 72 hours $(P<0.01)[30]$. These children had raised ICP that was refractory to other management strategies including the use of bolus infusions of mannitol. Among 23 children with cerebral malaria, a dose-response effect with use of boluses of mannitol was observed in moderately raised ICP (ICP $>20 \mathrm{mmHg}, \mathrm{CPP}<50 \mathrm{mmHg}$ ) but not with severely raised ICP (ICP $>40 \mathrm{mmHg}$, CPP $<40 \mathrm{mmHg}$ ) [1]. In a study of 3 children with TBI, oral glycerol was shown to reduce ICP by at least $50 \%$ within the first half hour of administration and maximally after 60 minutes [31]. This reduction was not maintained beyond 90 minutes. A case report of two children with TBI showed a dose response relationship between both HS and mannitol, and ICP [34]. However, mannitol appeared to cause a reduction in CPP.

All the five studies that investigated HS $[26,29,30,33,34]$ demonstrated a dose-response effect on ICP irrespective of the saline concentrations.

\section{Mortality}

All the included studies reported mortality. However, in examining mortality, we only analyzed the RCTs since they were the only studies that had groups for comparison. The four RCTs [26-29] identified were heterogeneous in relation to the interventions used and could not be pooled for meta-analysis. In one multicentre trial on 654 children with bacterial meningitis, the mortality was lower in those given glycerol compared to placebo (RR $0.6495 \%$ CI $0.54,0.76)[28]$ and, in children given glycerol and dexamethasone combination compared to placebo (RR 0.79 95\%CI 0.68, 0.92) [28] (Figure 2). Our own analysis of this data suggests a lower mortality with use of glycerol and dexamethasone combination compared to glycerol alone (RR $0.8195 \%$ CI 0.67, 0.98). Another trial comparing the use of HS and ringer's lactate as resuscitative fluids in 32 children with TBI reported only 2 deaths which occurred in children receiving ringer's lactate [29]. Among 156 children with cerebral malaria (CM), there was no observed difference in mortality when a single bolus of mannitol was administered compared to normal saline (RR 0.81 95\%CI 0.60, 1.09) [27]; this trial was however not powered to detect a difference in mortality. In a clinical series of children with non-traumatic encephalopathies, there was less mortality with use of HS compared to mannitol (RR $0.4895 \%$ CI 0.34, 0.67) [32].

Table 2 Methodological assessment of clinical trials

\begin{tabular}{|c|c|c|c|c|}
\hline Study & $\begin{array}{c}\text { Fisher } \\
1992[26]\end{array}$ & $\begin{array}{c}\text { Namutangula } \\
2007 \text { [27] }\end{array}$ & $\begin{array}{c}\text { Peltola } \\
2007[28]\end{array}$ & $\begin{array}{c}\text { Simma } \\
1998[29]\end{array}$ \\
\hline Was the assignment to treatment groups truly random? & Y & Y & Y & Y \\
\hline Were participants blinded to treatment allocation? & N & Y & Y & Y \\
\hline Was allocation to treatment groups concealed from the allocator? & $U$ & Y & Y & N \\
\hline Were the outcomes of people who withdrew described and included in the analysis? & Y & Y & Y & Y \\
\hline Were those assessing outcomes blind to the treatment allocation? & U & Y & Y & N \\
\hline Were the control and treatment groups comparable at entry? & N & Y & Y & Y \\
\hline Were the groups treated identically other than for the named interventions? & Y & Y & Y & Y \\
\hline Were outcomes measured in the same way for all groups? & Y & Y & Y & Y \\
\hline Were outcomes measured in a reliable way? & Y & Y & Y & Y \\
\hline Was appropriate statistical analysis used? & $\mathrm{Y}$ & $\mathrm{Y}$ & $\mathrm{Y}$ & $\mathrm{Y}$ \\
\hline
\end{tabular}

${ }^{*} \mathrm{Y}=\mathrm{Yes}, \mathrm{N}=\mathrm{No}, \mathrm{U}=$ Unclear 
Table 3 Methodological assessment of cohort study

\begin{tabular}{lc}
\hline Study & $\begin{array}{c}\text { Yildizdas } \\
\text { 2006 } \\
\text { [32] }\end{array}$ \\
\hline $\begin{array}{l}\text { Is sample representative of patients in the populations as a } \\
\text { whole? }\end{array}$ & $\mathrm{Y}$ \\
Are the patients at a similar point in the course of their & $\mathrm{Y}$ \\
condition/illness? & $\mathrm{U}$ \\
Has bias been minimized in relation to selection of cases & $\mathrm{N}$ \\
and of controls? & $\mathrm{Y}$ \\
Are confounding factors identified and strategies to deal & $\mathrm{Y}$ \\
with them stated? & $\mathrm{Y}$ \\
Are outcomes assessed using objective criteria? & \\
Was follow up carried out over a sufficient time period? & $\mathrm{Y}$ \\
Were the outcomes of people who withdrew described and \\
included in the analysis?
\end{tabular}

${ }^{*} \mathrm{Y}=$ Yes, $\mathrm{N}=$ No, $\mathrm{U}=$ Unclear

\section{Neurological sequelae}

Four studies reported on neurological sequelae $[1,28,30,33]$, but only one of these studies was a clinical trial [28]. In this trial examining the use of glycerol and dexamethasone in 654 children with bacterial meningitis, poor outcome (defined as severe neurological sequelae and profound hearing loss) was lower in the glycerol group (RR $0.5895 \%$ CI $0.50,0.67$ ) and the glycerol and dexamethasone combination (RR 0.55 95\%CI 0.47, 0.65) compared to placebo [28]. This lower risk was similarly observed when severe neurological sequelae were examined alone. No significant differences were observed between the glycerol and the glycerol and dexamethasone combination.

\section{Resolution of Coma}

Only one study, a clinical trial of mannitol on children with CM, examined resolution of coma as an outcome measure [27]. There was no difference between use of mannitol and placebo in coma resolution [median (IQR duration 20.5 (14.1-53.4) and 18.9 (10.0-38.0) hours respectively $(\mathrm{p}=0.11)$.

\section{Discussion}

We identified four RCTs, one of which was on children with non-traumatic encephalopathies. Each trial compared different agents and could not be pooled for meta-analysis. We examined 3 prospective observational studies, 2 retrospective studies and 1 case report. In our evaluation, HS appeared to achieve greater reduction in ICP than other osmotic agents. Oral glycerol was associated with less mortality and neurological sequelae when compared to placebo among children with acute bacterial meningitis. The only study that examined resolution of coma did not show any difference between the osmotic agent, mannitol, and placebo.

There was a dose response in the reduction of ICP with use of all the agents examined. However, ICP is a dynamic entity and single measurements on admission indicating raised ICP do not predict clinical outcome [1]. The analysis of ICP measurements therefore often consists of determining the duration of time that ICP is above a certain threshold [35]. It is desirable that interventions result in sustained reductions in ICP. And so, whilst all agents in the studies reviewed exhibited a dose response effect, this was transient in a number of cases. Continuous infusions of HS appeared to achieve sustained reduction in ICP. However, the advantage of different rates of administration can only be reliably investigated in clinical trials that specifically investigate the different modes and rates of administration of a particular intervention.

Hypertonic saline was shown to reduce ICP more than either normal saline [26] or ringer's lactate solutions [29]. When compared to mannitol, HS maintained or improved CPP, an important determinant of neurological outcome [34]. This effect is particularly important in

Table 4 Methodological Assessment of descriptive and case series studies

\begin{tabular}{|c|c|c|c|c|c|}
\hline Study & $\begin{array}{l}\text { Berger } 2002 \\
{[34]}\end{array}$ & $\begin{array}{c}\text { Peterson } \\
2000 \\
{[33]} \\
\end{array}$ & $\begin{array}{c}\text { Khanna } \\
2000 \\
{[30]}\end{array}$ & $\begin{array}{c}\text { Newton } \\
1997 \\
{[1]} \\
\end{array}$ & $\begin{array}{c}\text { Wald } \\
1982 \\
{[31]} \\
\end{array}$ \\
\hline Was study based on a random or pseudo-random sample? & N & N & N & N & N \\
\hline Were the criteria for inclusion in the sample clearly defined? & Y & Y & Y & Y & N \\
\hline Were confounding factors identified and strategies to deal with them stated? & N & N & $U$ & $U$ & U \\
\hline Were outcomes assessed using objective criteria? & Y & Y & Y & Y & Y \\
\hline If comparisons were being made, were there sufficient descriptions of the groups? & Y & Y & Y & Y & Y \\
\hline Was follow up carried out over a sufficient time period? & Y & Y & Y & Y & Y \\
\hline $\begin{array}{l}\text { Were the outcomes of people who withdrew described and included in the } \\
\text { analysis? }\end{array}$ & Y & Y & Y & Y & Y \\
\hline Were outcomes measures in a reliable way? & Y & Y & Y & Y & Y \\
\hline Was appropriate statistical analysis used? & Y & Y & Y & Y & Y \\
\hline
\end{tabular}

${ }^{*} \mathrm{Y}=\mathrm{Yes}, \mathrm{N}=\mathrm{No}, \mathrm{U}=$ Unclear 


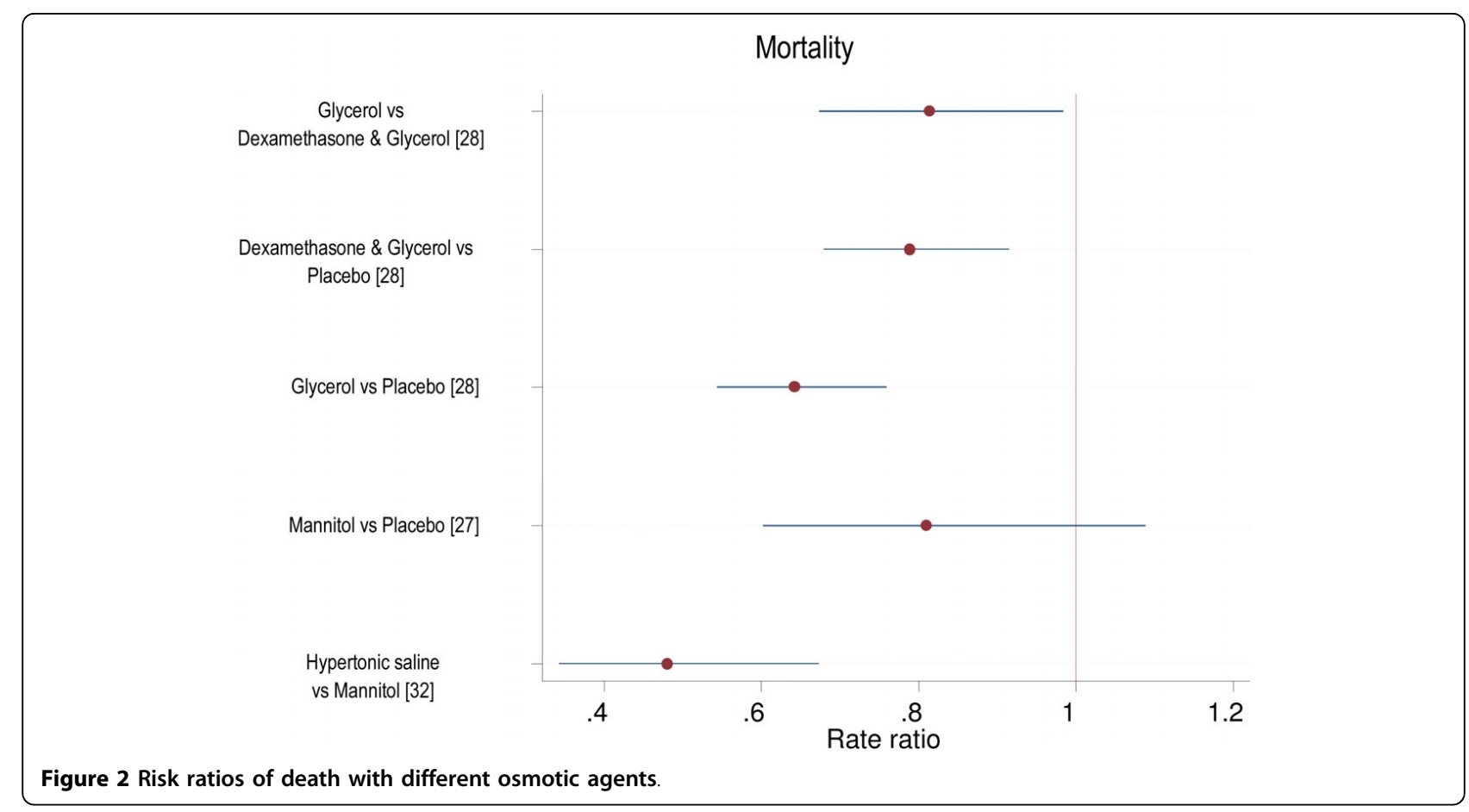

acute encephalopathies associated with volume deficits such as TBI and cerebral malaria. Theoretically, HS as a crystalloid may equilibrate freely throughout brain tissue in encephalopathies associated with impairment of the blood brain barrier such as meningitis, thus aggravating ICP. However there is little evidence of this phenomenon in the studies that we reviewed.

There was a lower relative risk of death with HS compared to mannitol [32], and with oral glycerol or a combination of oral glycerol and dexamethasone compared to placebo [28]. In the latter trial, glycerol, either alone or combined with dexamethasone, was associated with fewer neurological sequelae compared to placebo. There appeared to be less mortality when glycerol was used in combination with dexamethasone compared to glycerol used alone. Glycerol, given orally, allows for a convenient mode of administration considering resource poor settings. This trial was carried out across 10 institutions in different countries and the consistency of care is likely to have been difficult to maintain. Studies needed to examine effects of osmotic agents on neurological outcome would require large samples sizes and longer durations of follow up than those of the studies we examined.

We restricted our search to studies that were published in the English and French languages after 1966, potentially missing out on a number of studies in other languages. However, it is unlikely that a search of literature before 1966 could have yielded adequately reported studies on children. Most of the studies that we have included are observational studies and thus limit the validity of our analysis.

In one study that we included [29], the osmotic agent was examined for use as a resuscitative fluid, not for treatment of ICP. Nevertheless, this study provided data on the use of osmotic agents and suggested a more effective mode of administration of osmotic agents, supporting continuous rather than bolus infusions. We have included one study that had a mixed population of children and adults [31]. In this study, some of the data on children is provided separately. In another study, young infants were also recruited but their results were not analysed separately [32]. Young infants have an immature nervous system and a patent anterior fontanelle, and the dynamics of ICP is different from that of older children. In addition, scoring them for coma using a similar scale as for older children could be misleading. Another study investigated children with a varied aetiology of acute encephalopathies [36]. Even so, the pathophysiology of raised ICP appears to be similar irrespective of aetiology.

A clinical trial examining the use of oral glycerol and rectal paracetamol among children with meningitis in Malawi (ISRCTN70121840) is ongoing and when complete, may provide more insight on the use of osmotic agents in children.

\section{Conclusion}

The review supports the use of oral glycerol in children with acute bacterial meningitis and the use of 
hypertonic saline in acute traumatic and non-traumatic encephalopathies. However, the evidence presented is not sufficient to provide guidelines. Further clinical trials are needed to examine the safest and most efficacious concentrations of the various agents, particularly hypertonic saline. Such studies will also guide on the appropriate routes of administrations and the optimum rates of administration of these agents. Multi-centre trials may be necessary to achieve adequate sample sizes.

Additional file 1: Characteristics of included studies. This table provides a summary of the characteristics of included studies, including details regarding participants, interventions, comparison groups, outcome, and the study design. The authors' conclusions and the reviewers' comments on each paper are also included

\section{Acknowledgements}

This study is published with the permission of the Director of Kenya Medical Research Institute. The Joanna Briggs Institute supported us in the research and write up of the review.

\section{Author details}

${ }^{1}$ Centre for Geographic Medicine Research (Coast), KEMRI-Wellcome Trust Collaborative Research Programme, Kilifi, Kenya. ${ }^{2} J$ oanna Briggs Evidence Synthesis Group, Kilifi, Kenya. ${ }^{3}$ The International Centre of Insect Physiology and Ecology, Kenya. ${ }^{4}$ Department of Paediatrics and Child Health, Mulago Hospital, Makerere University School of Medicine, Kampala, Uganda. ${ }^{5}$ London School of Hygiene and Tropical Medicine, London, UK. ${ }^{6}$ Department of Neurosciences, Institute of Child Health, University College London, UK.

\section{Authors' contributions}

SG conceived the review. SG, HG and LM researched for the review. HG provided statistical support. All the authors participated in drafting the manuscript. All the authors have read the approved final version.

\section{Authors' information}

SG, HG and LM are members of the Joanna Briggs Institute (JBI) evidence synthesis group (Kenya chapter) and were supported by the JBI program. CN is supported by the Wellcome Trust, UK (070114).

\section{Competing interests}

The authors declare that they have no competing interests.

Received: 21 July 2009 Accepted: 17 April 2010 Published: 17 April 2010

\section{References}

1. Newton CR, Crawley J, Sowumni A, Waruiru C, Mwangi I, English M, Murphy S, Winstanley PA, Marsh K, Kirkham FJ: Intracranial hypertension in Africans with cerebral malaria. Arch Dis Child 1997, 76(3):219-226.

2. Goitein KJ, Amit Y, Mussaffi H: Intracranial pressure in central nervous system infections and cerebral ischaemia of infancy. Arch Dis Child 1983, 58(3):184-186.

3. Solomon T, Dung NM, Kneen R, Thao le TT, Gainsborough M, Nisalak A, Day NP, Kirkham FJ, Vaughn DW, Smith S, et al: Seizures and raised intracranial pressure in Vietnamese patients with Japanese encephalitis. Brain 2002, 125(Pt 5):1084-1093.

4. Papo I, Caruselli G, Luongo A: Intracranial pressure in children and adolescents with severe head injuries. J Neurosurg Sci 1982, 26(3):193-198.

5. Lindvall P, Ahlm C, Ericsson M, Gothefors L, Naredi S, Koskinen LO: Reducing intracranial pressure may increase survival among patients with bacterial meningitis. Clin Infect Dis 2004, 38(3):384-390.

6. Nara I, Shiogai T, Hara M, Saito I: Comparative effects of hypothermia, barbiturate, and osmotherapy for cerebral oxygen metabolism intracranial pressure, and cerebral perfusion pressure in patients with severe head injury. Acta Neurochir Suppl 1998, 71:22-26.
7. Oertel M, Kelly DF, Lee JH, McArthur DL, Glenn TC, Vespa P, Boscardin WJ, Hovda DA, Martin NA: Efficacy of hyperventilation, blood pressure elevation, and metabolic suppression therapy in controlling intracranial pressure after head injury. J Neurosurg 2002, 97(5):1045-1053.

8. Rutigliano D, Egnor MR, Priebe CJ, McCormack JE, Strong N, Scriven RJ, Lee TK: Decompressive craniectomy in pediatric patients with traumatic brain injury with intractable elevated intracranial pressure. J Pediatr Surg 2006, 41(1):83-87, discussion 83-87.

9. Zornow MH, Oh YS, Scheller MS: A comparison of the cerebral and haemodynamic effects of mannitol and hypertonic saline in an animal model of brain injury. Acta Neurochir Suppl (Wien) 1990, 51:324-325.

10. Regoli F, Winston GW: Quantification of total oxidant scavenging capacity of antioxidants for peroxynitrite, peroxyl radicals, and hydroxyl radicals. Toxicol Appl Pharmacol 1999, 156(2):96-105.

11. Newton CR, Krishna S: Severe falciparum malaria in children: current understanding of pathophysiology and supportive treatment. Pharmacol Ther 1998, 79(1):1-53

12. Soriano SG, McManus ML, Sullivan LJ, Rockoff MA, Black PM, Burrows FA: Cerebral blood flow velocity after mannitol infusion in children. Can J Anaesth 1996, 43(5 Pt 1):461-466.

13. Shackford SR, Zhuang J, Schmoker J: Intravenous fluid tonicity: effect on intracranial pressure, cerebral blood flow, and cerebral oxygen delivery in focal brain injury. J Neurosurg 1992, 76(1):91-98.

14. Silva JC, de Melo Tavares de Lima F, Valenca MM, de Azevedo Filho HR: Hypertonic saline more efficacious than mannitol in lethal intracranial hypertension model. Neurol Res 2009

15. Segal S, Gallagher AC, Shefler AG, Crawford S, Richards P: Survey of the use of intracranial pressure monitoring in children in the United Kingdom. Intensive Care Med 2001, 27(1):236-239.

16. Jacinda Wilson SH, Sandy Sacre, Jenny Abbey: Appropriateness of using a symbol to identify dementia and/or delirium: a systematic review. Dementia Collaborative Research Centre 2007, 1-61.

17. Cruz J, Nakayama P, Imamura JH, Rosenfeld KG, de Souza HS, Giorgetti GV Cerebral extraction of oxygen and intracranial hypertension in severe, acute, pediatric brain trauma: preliminary novel management strategies. Neurosurgery 2002, 50(4):774-779, discussion 779-780.

18. Kingston ME: Experience with urea in invert sugar for the treatment of cerebral malaria. J Trop Med Hyg 1971, 74(11):249-252.

19. Prabhakaran P, Reddy AT, Oakes WJ, King WD, Winkler MK, Givens TG: A pilot trial comparing cerebral perfusion pressure-targeted therapy to intracranial pressure-targeted therapy in children with severe traumatic brain injury. J Neurosurg 2004, 100(5 Suppl Pediatrics):454-459.

20. Mickell JJ, Reigel DH, Cook DR, Binda RE, Safar P: Intracranial pressure: monitoring and normalization therapy in children. Pediatrics 1977 59(4):606-613.

21. James HE: Methodology for the control of intracranial pressure with hypertonic mannitol. Acta Neurochir (Wien) 1980, 51(3-4):161-172.

22. James HE, Langfitt TW, Kumar VS, Ghostine SY: Treatment of intracranial hypertension. Analysis of 105 consecutive, continuous recordings of intracranial pressure. Acta Neurochir (Wien) 1977, 36(3-4):189-200.

23. Vialet R, Albanese J, Thomachot L, Antonini F, Bourgouin A, Alliez B, Martin C: Isovolume hypertonic solutes (sodium chloride or mannitol) in the treatment of refractory posttraumatic intracranial hypertension: $2 \mathrm{~mL} / \mathrm{kg} 7.5 \%$ saline is more effective than $2 \mathrm{~mL} / \mathrm{kg} \mathrm{20 \%}$ mannitol. Crit Care Med 2003, 31(6):1683-1687

24. Marshall LF, RW SM, Rauscher LA, Shapiro HM: Mannitol dose requirements in brain-injured patients. J Neurosurg 1978, 48(2):169-172.

25. MacDonald JT, Uden DL: Intravenous glycerol and mannitol therapy in children with intracranial hypertension. Neurology 1982, 32(4):437-440.

26. Fisher B, Thomas D, Peterson B: Hypertonic saline lowers raised intracranial pressure in children after head trauma. J Neurosurg Anesthesiol 1992, 4(1):4-10.

27. Namutangula B, Ndeezi G, Byarugaba JS, Tumwine JK: Mannitol as adjunct therapy for childhood cerebral malaria in Uganda: a randomized clinical trial. Malar J 2007, 6:138.

28. Peltola H, Roine I, Fernandez J, Zavala I, Ayala SG, Mata AG, Arbo A, Bologna R, Mino G, Goyo J, et al: Adjuvant glycerol and/or dexamethasone to improve the outcomes of childhood bacterial meningitis: a prospective, randomized, double-blind, placebo-controlled trial. Clin Infect Dis 2007, 45(10):1277-1286. 
29. Simma B, Burger R, Falk M, Sacher P, Fanconi S: A prospective, randomized, and controlled study of fluid management in children with severe head injury: lactated Ringer's solution versus hypertonic saline. Crit Care Med 1998, 26(7):1265-1270.

30. Khanna S, Davis D, Peterson B, Fisher B, Tung H, O'Quigley J, Deutsch R: Use of hypertonic saline in the treatment of severe refractory posttraumatic intracranial hypertension in pediatric traumatic brain injury. Crit Care Med 2000, 28(4):1144-1151.

31. Wald SL, McLaurin RL: Oral glycerol for the treatment of traumatic intracranial hypertension. J Neurosurg 1982, 56(3):323-331.

32. Yildizdas $D$, Altunbasak $\mathrm{S}$, Celik U, Herguner O: Hypertonic saline treatment in children with cerebral edema. Indian Pediatr 2006, 43(9):771-779.

33. Peterson B, Khanna S, Fisher B, Marshall L: Prolonged hypernatremia controls elevated intracranial pressure in head-injured pediatric patients. Crit Care Med 2000, 28(4):1136-1143.

34. Berger S, Schwarz M, Huth R: Hypertonic saline solution and decompressive craniectomy for treatment of intracranial hypertension in pediatric severe traumatic brain injury. J Trauma 2002, 53(3):558-563.

35. Czosnyka M, Hutchinson PJ, Balestreri M, Hiler M, Smielewski P, Pickard JD: Monitoring and interpretation of intracranial pressure after head injury. Acta Neurochir Suppl 2006, 96:114-118.

36. Procaccio F, Menasce G, Sacchi L, Boselli L: Effects of thiopentone and mannitol on cerebral perfusion pressure and E.E.G. in head injured patients with intracranial hypertension. Agressologie 1991, 32(8-9 Spec No):381-385.

\section{Pre-publication history}

The pre-publication history for this paper can be accessed here: http://www.biomedcentral.com/1471-2431/10/23/prepub

doi:10.1186/1471-2431-10-23

Cite this article as: Gwer et al:: The role for osmotic agents in children with acute encephalopathies: a systematic review. BMC Pediatrics 2010 10:23.

\section{Submit your next manuscript to BioMed Central and take full advantage of:}

- Convenient online submission

- Thorough peer review

- No space constraints or color figure charges

- Immediate publication on acceptance

- Inclusion in PubMed, CAS, Scopus and Google Scholar

- Research which is freely available for redistribution

Submit your manuscript at www.biomedcentral.com/submit 